\title{
EMPLOYEE ENGAGEMENT IN VIRTUAL INDUSTRIAL ENVIRONMENT
}

\section{DINESH B. HANCHATE ${ }^{1} \&$ VAISHALI RAHATE ${ }^{2}$}

${ }^{I}$ Dean, IIIC, VKBIET, Baramati, Pune, MH, India

${ }^{2}$ Dean, Academics (DMIMS), Datta Meghe Institute of Management, Studies, Nagpur, MH, India

\begin{abstract}
Information and Communication Technologies (ICT) in the industry have made distance working possible through the use of a Virtual Industrial (VI) environment. It has various advantages like location independence and storage of the work done, but the absence of a project manager may be felt and the industrial sections may become monotonous. This paper discusses the process of Employee Engagement (EE) in a virtual industrial environment. Based on our experience in both conventional and e-working environment, we propose some techniques which can help to enliven the VI environment, make the working more interesting for the employee and lead to effective Employee Engagement (EE).
\end{abstract}

KEYWORDS: Information and Communication Technologies (ICT), Employee Engagement (EE), Virtual Industrial (VI)

Received: Jun 14, 2021; Accepted: Jul 04, 2021; Published: Jul 26, 2021 ; Paper Id.: IJIETDEC20212

\section{INTRODUCTION}

Widespread utilization of Information and Communication Technologies (ICT) in the industry makes distance working feasible in the form of e-working, web based working, computer based training and virtual industrial work. These technologies are commonly deployed in most corporate scenarios. To get the milstones and success in this eworking, we are bounded by some replicate traditional industrial methods and that we cannot do it in ICT. Pedagogical principles and practices with their relation of some long-held myths and assumptions force ICT to review it. A key issue is the evolution of the project manager's role, with rethinking product presentation and delivery in such a new ICT environment.

Nowadays working and training is one of the most major concerns with high workforce turnaround and rotation and people distributed across geography in a corporate environment [1]. Flexible working and delivery are also becoming increasingly popular. Flexible working is an employee centered form of industry.[2, 3] On the other hand flexible delivery is defined as the provision of working which does not require the employee to be present at a particular place or time. Flexible delivery is a direct consequence of the way industry technologies are changing industry [4]. A virtual industrial environment comes with its own advantages like catering to distant locations and converted to audio-video format, which can be stored for later reuse. Such an environment focuses on content delivery, but turns out to be monotonous and is not as effective as a traditional industrial environment. Employees also miss the presence of a project manager.

The paper is structured as follows. In sections 2 and 3 we give a brief overview of e-working in the current context and virtual industrial environment respectively. Section 4 focuses on the Employee Engagement process in a virtual industrial scenario. In section 5 we discuss our observations regarding employees and propose some techniques for effective employee engagement. Finally, in section 6 we give a brief idea about the future work and 
conclude the paper.

\section{E-WORKING}

To get enhanced knowledge with skills (cognitive, psychometric) including online based or mixed based models (blended working), E-working style must take into consideration the utilization of ICT to impart a broad array of solutions. The latter uses a combination of e-working media, interspersed with instructor led working. Some general benefits of e-working includes lower costs, anywhere and anytime access. So, the working style and it's contents may be customized to catagorically classified industrial working needs [5, 6]. E-working has made possible the creation of virtual industries that provide distance training degrees. In a virtual industry, the employee connects to a virtual region and area with a different campus that provides a virtal working environment and other complementary services like mail, discussion forum and a mentor.

The online industry is not only the downloading of information followed by the passive and solitary activity of reading a computer screen. Instead, online industry advances the product management principles of constructive working through the facilitation of discussion with the instructor as well as other employees. Hence training in a virtual region and area with the different campus is quite different from training in a conventional traditional environment. There is temporal and spatial asynchrony between project managers and employees and the employee profile is usually different, having time constraints and responsibilities. The risk is involved even we have the potential advantages of Web-based services and delivery, there are also risks involved [7]. In order to support active working, virtual project setup should provide more than knowledge with statical representation. With virtual work traditional industrial activities or services such as analysis, design, testing and on shop working are replaced by Web-based counterparts. The industry literature suggests that employees who are actively engaged in the working process will be more likely to achieve success. It is therefore the continuing challenge of any industrial program to ensure that employees are involved and bear part of the responsibility of working.

\section{VIRTUAL INDUSTRY}

Many working environments have begun to put the distance industry to practice through intranet or internet, by hoping to increase working efficiency. A virtual industry allows a facilitator and trainees to communicate in a virtual environment and deliver and attend training remotely. It is both ways in audio/video communication between the trainer and employees [8]. Employees can take part in the training from different locations and even trainers can jointly train from different locations. This environment is suitable for a scenario with very large employee numbers who can attend from two separate rooms. It is also applicable for undertaking training from locations inaccessible for employees for security or other reasons like ODC- Offshore Development Centers. This set up is also ideal for Virtual Companies, many of which exist across the globe $[9,10,11]$. Using Virtual industrial environment for training, one can drastically decrease the cost and improve the availability of training. A virtual industrial tool also provides a facility to record the working [12,13]. These working are available later to download or stream as desired, thus providing a reuse capability. Employees who could not attend the section can view the working at leisure or in case they have doubts.

Since a virtual industrial environment is very much different from the traditional face-to-face communication model, the design of interactivity becomes an important subject [14]. Each project manager is responsible to guide the employee in the working process, acting as a knowledge contents facilitator. Hence, project managers using a virtual 
industrial need to inculcate specialized skills with abilities to get the accomplishment in training the employees without their physical presence in the section [15]. They need to have constant interaction with the employees so that employees feel the project manager's support. Probably identifying the employees with their names is an added advantage.

\section{KNOWLEDGE DELIVERY IN A VC}

A typical virtual classroom environment consists of a set of users having a multimedia PC with VC software like Aspen, Centra software which we have used. The VC classes was conducted for BITS Patni collaboration M.S. Software Engineering course from Mumbai and with students (same is applicable to employees as trainee) attending from Patni Computer systems Ltd. offices situated at Pune, Bangalore, Noida and Hyderabad etc. This course is run by BITS Pilani, Distance Education for Patni employees as a two year program for Engineers and four year program for Science and Commerce graduates. It is a very attractive scheme for employees who want to enhance their qualifications along with their jobs. The available setup allows trainee/employees/students to take part in the online sessions from different physical locations and enables faculty to undertake joint lectures for people located at different geographical locations, be it from offices with intranet - LAN or WAN or even from home.

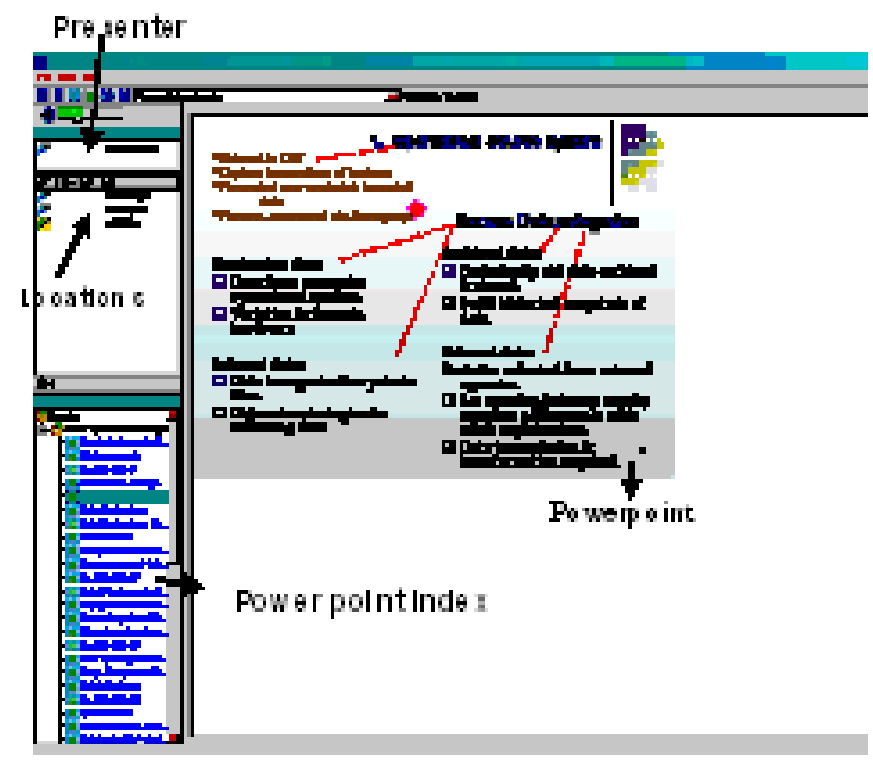

Figure 1: VC Screen

The example screen shot of the trainer's screen is shown in figure 1. We can see the window with training presentation in MS Power Point on the right screen and a slide navigator to the left of the screen. The employees from various locations attend the session as indicated. The trainer can upload the presentation, teach by sharing any application running on the desktop or open a web page.

The trainer has control of the presentation as shown in figure 2. In a virtual system, changing between modes of learning can easily be supported by appropriate navigation support. The trainer can highlight or put a marker to the point being currently discussed. Additionally, the whiteboard can be used to explain concepts by diagramming the desired information. 


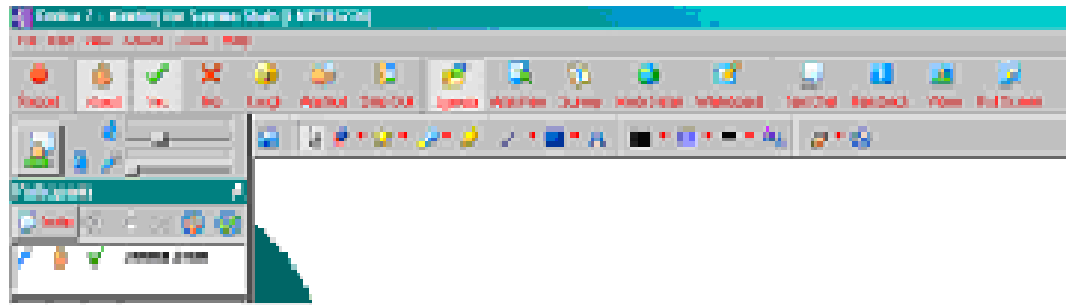

Figure 2: VC Software Navigation Facility

To enable the students/employees/trainee to send any information about the audibility and understanding during the session the following icons are available in the screens of both the teacher/trainer and the participant as shown in figure 3.

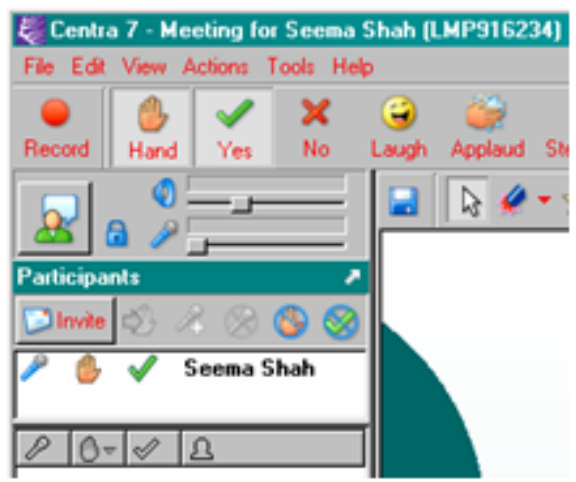

Figure 3: VC Software Icons

In case of unavailability of mikes, the students/employees/trainee can communicate with each other and the teacher/trainer through text chat. Using the above mentioned icons, the students/employees/trainee can have full communication with the trainer and can benefit fully from the lecture. The teacher/trainer can conduct a survey or take online feedback per location.

\section{TECHNIQUES FOR IMPROVING EMPLOYEE ENGAGEMENT}

A virtual industrialist is beneficial to train employees from remote locations, but yet employees prefer instructor led working. This is because VI is working to become monotonous and the employees lose attention very fast. Hence, feedback from employees indicates that instructor led working is preferable to effective working. The employees distinctly feel the absence of the project manager. Hence we suggest here techniques enliven the VI environment, make the working more interesting for the employee and lead to effective employee engagement.

\section{Interactivity}

The industry literature suggests that employees who are actively engaged in the working process will be more likely to achieve success. [16] Working is a two-way communication and interactivity is a process to enhance communication among instructors, employees, working materials, and interfaces. Interactivity is also a means for engaging and encouraging an employee to think critically and apply the concepts to what is understood. Hence an interactive environment with a stream of questions will assist in effective working. In a VI environment, the employees were given time to adjust to the job scheduling the questions. They could do so orally using the mike or one at a time or many of them could type in their text chat box which was continuously seen by all. In such cases the project manager was responsible to 
read the answers in a specific order so as to explain the Job or manufacturing concepts. This led to the employee asking related query or wanting to share his/her experience with the industrial section. Obviously, the project manager needs to take extreme care to keep within the bounds of the agenda else the work time session may extend beyond time and even beyond the work area.

\section{Collaborative Working}

Collaborative working is defined as a situation where two or more people attempt to do something together [17,18]. Much research is carried out regarding employees' queries, task generation and collaborative working [19,20,21]. We can also adopt the collaborative working technique by asking employees to make groups, discuss a specific Jobe/Machine/Product topic (chat rooms) and then join together in a case study discussion and its implementation. The employees can also spend time in conversation with each other at each location whenever some critical problem is posed to them. Some employees even can share their experiences from projects for further discussion, which is appreciable by the subordinate. The overall oral feedback from the employees from various studies and experiments indicates that the interactive and Collaborative working approach definitely enhances active working among the employees in a virtual industrial environment [22].

\section{CONCLUSIONS}

With recent advances in technology use of Virtual Industry are on the rise. They differ greatly from traditional industrials in terms of content and delivery because the employees are dispersed across different geographical locations. Hence a project manager needs to play a more critical role in terms of product quality and delivery. To avoid issues like monotony and physical absence of a project manager, we suggest the integration of the Interactive and Collaborative working approach in a virtual industrial environment. Based on the experiences of well known industrialists, we are confident that the integration of these techniques will enliven the VI environment, make the working more interesting for the employee and lead to effective employee engagement.

\section{ACKNOWLEDGEMENTS}

The authors are grateful for valuable support from Dr. Seema Shah, Director, B.Tech Integrated Programme, MPSTME, NMIMS University, Mumbai.

\section{REFERENCES}

1. Nebolsky, Ye, Petrushin, Gershman; Using Virtual Worlds for Corporate training, ICALT 2003.

2. Marjanovic, Orlowska, Making Flexible Working More flexible, 2000 IEEE

3. https://www.jaluch.co.uk/hr-blast/10-top-tips-on-how-to-make-flexible-working-work-in-your-business/

4. Nunnan, Flexible Delivery- What is it and Why is it a part of the current industrial dispute?. HERDSA Annual conference Different Approaches: Theory and Practice in Higher Industry, 1996.

5. Jennifer Thomas, Technology Integrated Sectiones Versus Traditional Sections and their Impact on User Performance and Perception; ICCE'02

6. https://www.knowledgehut.com/blog/project-management/how-to-become-a-project-manager-ultimate-guide

7. Nian-Shing Chen, Yeuh-Chun Shih; Stream Based Lecturing System and Its Instructional Design IEEE 2001 
8. Krukowski, Kale; Virtual Industrial, IEEE 2001.

9. http://www.vu.msu.edu/

10. http://cvu.strath.ac.uk

11. https://www.researchgate.net/publication/334143669_An_Introduction_to_the_Special_Issue_Virtual_Reality_in_Marketing Definition_Theory_and_Practice

12. Stavros Filippidis, Ioannis Tsoukalas; Using Digital video as an Asynchronous Method of instruction, ICALT'03

13. https://www.constructconnect.com/blog/technology-reshaping-construction-industry

14. Irfan Naufal Umar; Sajap Maswan, "The Effects of Guided Inquiry Approach in a Web-based Working Environment on the Achievement of Employees with Different Cognitive Style”, ICALT,2006.

15. Juei-ni Sun Yu-chen Hsu, „,The Effect of Interactivity on Web-based Instruction Employees' Attitude, Satisfaction, and Performances", ICALT, 2005.

16. Mandi Axmann, "Effective Working Strategies for the On-line Working Environment: Including the Lost Employee", ICALT, 2001 .

17. Sung-Bin Chang, Kuan-jung tung, Tak-Wai Chan, A Working Strategy of Employee Question Generation to Enhance Comprehension of Working materials in a digital Industrial Environment, ICALT'05

18. https://www.worldcat.org/title/collaborative-learning-cognitive-and-computational-approaches/oclc/53956429

19. Belainch, Wisher, Orvis; A question Collaboration Approach to Web Based Working, American journal of distance industry, 2004

20. https://www.researchgate.net/publication/321132224_Peer_assessment_in_a_projectbased_engineering_course_comparing_between_on-campus_and_online_learning_environments

21. Artur Krukowski, Izzet Kale, "Virtual Industrial”, ICALT, 2001.

22. Dinesh A. Zende, Dinesh B. Hanchate, "A Cost Effective Solution to Traditional Classroom Teaching", Conference: National Conference on "Recent trends in Information Technology based education and training", Bannari Amman Institute of Technology Sathyamangalam, Tamil Nadu, October 2005

23. Naidu, Jyoti. "Curbing staff turnover through employee engagement in the retail sector of Nagpur." International Journal of Human Resource Management and Research (IJHRMR) 6.3 : 29-40.

24. Kanwar, Dipti, and Jyoti Jain. "An Empirical Study on Practice of Employee Engagement Activities in Hospitality Industry." International Journal of Human Resource Management and Research (IJHRMR) 8 : 131-138.

25. Das, Sarit Prava, and Parna S. Mishra. "Antecedents and consequences of employee engagement: A critical analysis of literature review." International Journal of Human Resources Management 3.2 : 73-86.

26. Battu, Nagaraju, and Shriram Darbha. "Holistic Employee Engagement for Achieving Peak Performance and Overall Satisfaction." International Journal of Business and General Management (IJBGM) 6.5 : 23-32. 